\title{
AS ELEIÇÕES DE 2010 E O QUADRO PARTIDÁRIO
}

\author{
FERNANDO LIMONGI E RAFAEL CORTEZ
}

\section{RESUMO}

As eleições presidenciais têm se resumido a uma disputa entre PT e PSDB. Nenhuma candidatura alternativa foi capaz de ameaçar o controle desses partidos sobre a maioria dos eleitores. A estruturação das eleições presidenciais repercute sobre as disputas pelos governos estaduais, fazendo com que estas obedeçam à mesma clivagem básica. A estratégia dos partidos, negociando o lançamento e a retirada de candidaturas, é a chave para se entender a dinâmica da competição eleitoral no Brasil.

PALAVRAS-CHAVE: Eleições 2010; partidos; sistema partidário; democracia.

\section{ABSTRACT}

Presidential elections in Brazil have been regularly a dispute between PT and PSDB. No third alternative has been able to threaten the control these parties have over the majority of the electorate. The way presidential elections are structured has an influence over the elections at state level, reproducing the same pattern. The parties' strategy, negotiating the launching and withdrawal of candidacies, is the key to understanding the dynamics of electoral disputes in Brazil.

KEYWORDS: 2010 elections; political parties; party system; democracy.

Acampanha eleitoral de 2010 reservou suas emoções para o final. A oposição esperneou e temeu pelo seu futuro. Lula foi comparado a Chaves e o PT, ao PRI. O governo enxergou um complô organizado da mídia para deter as mudanças a favor dos mais desfavorecidos. O Poder Judiciário complicou as coisas e deixou a bola quicando na marca do pênalti. Abertas as urnas no primeiro turno, Marina surpreendeu. Falou-se em nova clivagem, até no surgimento de um voto pós-material no Brasil. A oposição, aliviada, recobrou suas forças, esqueceu-se dos temores que expressara quanto à sua própria sobrevivência e partiu para a luta. O governo, forçado a deixar o salto alto no armário, reviu sua estratégia. 
A conjuntura ocupa as atenções dos analistas. Não faltarão interpretações sobre o recado das urnas. Boa parte delas, como de costume, passará pelo desvendamento do que teria se passado na cabeça do eleitor. Contudo, já é hora de mudar o foco das análises, abrir a angulare firmar uma interpretação que privilegie as tendências de longo prazo. Afinal, desde a redemocratização, já foram seis eleições presidenciais ${ }^{1}$.

Vistas em conjunto, as eleições presidenciais revelam uma clara estruturação: PT e PSDB foram os únicos a concorrer em todas elas, tendo chegado à frente em cinco delas. Eleições presidenciais no Brasil têm sido eleições bi-partidárias ${ }^{2}$. Além disso, dado que a presidência é o ponto mais importante do sistema político brasileiro, o entendimento da evolução do quadro partidário nacional deve partir desta constatação. As eleições presidenciais organizam e estruturam as demais disputas. É o prêmio principal; os demais são subsidiários.

A clivagem nacional PT-PSDB, progressivamente, tem passado a regere ditaro tom das disputas estaduais. Cada um destes partidos comanda um bloco de aliados, incluindo aí o PMDB que, estado a estado, opta por um dos lados. Em 2010 , essa clivagem organizou as disputas pelos governos estaduais, completando um processo em marcha desde pelo menos 1994. As eleições para o governo estadual também se tornaram bi-partidárias em quase todos os estados, espelhando a clivagem que domina as eleições presidenciais. Se PT ou PSDB não capitaneavam as coligações, estavam representados por seus aliados históricos (PSB e DEM, respectivamente) ou circunstancial (PMDB). Dessa forma, são cinco os partidos relevantes nas disputas pelo governo, mas eles nunca estão presentes no mesmo estado. As disputas estão integradas pelas estratégias seguidas pelos partidos. O lançamento de candidaturas nos dois planos é uma decisão interdependente. E os partidos têm retirado candidaturas estrategicamente em uma disputa para obter apoio em outra.

O quadro partidário nacional, portanto,é bem mais simples e inteligível do que as análises centradas nas disputas proporcionais deixam entrever. A fragmentação crescente na Câmara dos Deputados ganha novo significado quando se atenta para o fato de que uma boa parte dos partidos lá representados praticamente abandonou as disputas por cargos executivos. PP, PTB e PDT, para citar apenas os partidos de maior expressão, praticamente deixaram de lado as disputas por esses cargos. Quando muito, lançam candidatos a governos estaduais em poucos estados. Em geral, em estados pequenos ou onde não têm chances efetivas de chegar à vitória.

Assim, a tão temida fragmentação de nosso quadro partidário está limitada ao Poder Legislativo. A tendência nas eleições para os cargos executivos, os mais importantes para os partidos e para os eleitores, corre na direção oposta. Nas eleições que decidem efetivamente a distribuição do poder político, há concentração e não fragmentação.
[1] Agradecemos a Lara Mesquita, Danilo Buscatto Medeiros e Andrezza Davidian pela ajuda na organização dos dados.

[2] Não somos os primeiros a notar tal fato. Meneguello, Rachel. "Tendências eleitorais ao fim de 21 anos de democracia". In: Carlos Ranulfo Melo, C. R. e Sáez, Manuel Alcântara (orgs.).A democracia brasileira: balanço e perspectivas para o século 21. Belo Horizonte, Editora da UFMG, 2007, pp. 267-302.; Melo, Carlos Ranulfo. "Nem tanto ao mar, nem tanto à terra: elementos para uma análise do sistema partidário brasileiro. In: Melo e Sáez (orgs.), op. cit., pp. 374-404. 


\section{ELEIÇÕES PRESIDENCIAIS}

PT e PSDB são os principais protagonistas das eleições presidenciais, como mostra a Tabela 1. Desde 1994, dois partidos, e os mesmos dois partidos se revezaram nos dois primeiros lugares das eleições presidenciais. O PT, na realidade, tem desempenho superior ao do PSDB, posto que obteve a segunda colocação em 1989 quando o PSDB amargou a quarta colocação.

O predomínio alcançado por esses dois partidos contrasta com a instabilidade e a fragilidade relativa das "terceiras forças". Não apenas elas tendem a ficar muito distantes do segundo colocado, como também sua identidade varia de eleição para eleição. Somente Ciro Gomes candidatou-se duas vezes em seguida, e naufragou ao insistir. Se Marina e o PV terão outro destino é matéria aberta à especulação. Sua votação superou as expectativas em relação às projeções feitas pelas pesquisas, mas não excedeu em muito a de Garotinho em 2002. Além disso, a candidatura do PV nunca mostrou força para se habilitar a passar ao segundo turno. $\mathrm{O}$ candidato do PSDB manteve sempre uma vantagem confortável sobre sua adversária.

Como explicar o controle do PT e do PSDB sobre as eleições presidenciais? Por que foram capazes de estabelecer tal duopólio? A preferência dos eleitores não é capaz de explicar tais resultados. Eleitorado partidário fiel, um eleitor que vota sistematicamente no mesmo partido ao longo do tempo, seja o PT ou o PSDB, é uma minoria do eleitorado. Dados de identificação partidária indicam que eleitores partidários não passam de um terço do eleitorado. Ademais, não é claro que um eleitor identificado com um partido votará constantemente neste.As porcentagens de eleitores identificados a um partido tendem a variar com a conjuntura. Não servem, portanto, para prever o comportamento de longo prazo.

A flutuação de larga parcela do eleitorado tem sido decisiva para os resultados. Em 2002, larga parcela do eleitorado abandonou o PSDBe votou no PT, no PSB e no PPS. Em 2006, ainda que o PT tenha obtido praticamente a mesma votação de quatro anos antes, perdeu eleitores em alguns estratos e ganhou em outros. O PSDB, por seu turno, mesmo derrotado, cresceu em 2006, recuperando uma parte considerável dos eleitores que perdera.

Sem dúvida, o PT e o PSDB têm seus eleitores. Tudo indica que o PT os tem em maior número do que o PSDB. Mas eleitores fiéis que podem ser contados como votos certos para o partido em qualquer circunstância não são a maioria do eleitorado. Desse ponto de vista, terceiras forças têm espaço para crescer e podem até desbancar os dois líderes. Se não o fazem ou têm pequeno sucesso, é porque razões de outra ordem explicam a hegemonia desses dois partidos sobre as eleições presidenciais. 


\begin{tabular}{|c|c|c|c|c|c|c|}
\hline \multirow{2}{*}{ Ano } & \multicolumn{6}{|c|}{ Partido } \\
\hline & PT & PSDB & $3^{\circ}$ Lugar & PT + PSDB & $3^{\circ} / 2^{\circ}$ & $3^{\circ}$ Partido \\
\hline 1989 & 17,2 & 11,5 & 16,5 & 28,7 & 0,96 & PDT \\
\hline 1994 & 27,0 & 54,3 & 7,4 & 81,3 & 0,27 & PRONA \\
\hline 1998 & 31,8 & 53,1 & 10,9 & 84,9 & 0,21 & PPS \\
\hline 2002 & 46,4 & 23,2 & 17,9 & 69,6 & 0,77 & PSB \\
\hline 2006 & 48,6 & 41,6 & 6,8 & 90,3 & 0,16 & PSOL \\
\hline 2010 & 46,9 & 32,6 & 19,3 & 79,5 & 0,59 & PV \\
\hline
\end{tabular}

Fonte: Banco de Dados Eleitorais do Cebrap/CEM.

TABELA 2

Eleições Presidenciais - Candidatura Próprias

\begin{tabular}{|c|c|c|c|c|c|c|}
\hline \multirow{2}{*}{ Partido } & \multicolumn{6}{|c|}{ Ano } \\
\hline & 1989 & 1994 & 1998 & 2002 & 2006 & 2010 \\
\hline PT & $\mathrm{x}$ & $\mathrm{x}$ & $\mathrm{x}$ & $\mathrm{x}$ & $\mathrm{x}$ & $\mathrm{x}$ \\
\hline PDT & $\mathrm{x}$ & $\mathrm{x}$ & & & $\mathrm{x}$ & \\
\hline \multicolumn{7}{|l|}{ PSB } \\
\hline PCB/PPS & $\mathrm{x}$ & & $\mathrm{x}$ & $\mathrm{x}$ & & \\
\hline PSDB & $\mathrm{x}$ & $\mathrm{x}$ & $\mathrm{x}$ & $\mathrm{x}$ & $\mathrm{x}$ & $\mathrm{x}$ \\
\hline PMDB & $\mathrm{x}$ & $\mathrm{x}$ & & & & \\
\hline PTB & $\mathrm{x}$ & & & & & \\
\hline PFL/DEM & $\mathrm{x}$ & & & & & \\
\hline PDS/PP & $\mathrm{x}$ & $\mathrm{x}$ & & & & \\
\hline $\mathrm{N}^{\circ}$. Candidatos & 21 & 8 & 12 & 6 & 7 & 9 \\
\hline
\end{tabular}

Fonte: Banco de Dados Eleitorais do Cebrap/CEM.

A clivagem básica, portanto, não deve sua existência à cristalização das preferências do eleitorado. PT e PSDB não são partidos fortes, com enraizamento social suficiente para explicaro predomínio que têm exercido sobre as eleições presidenciais. Parte importante da resposta passa pela oferta de candidaturas (Tabela 2). PT e PSDB são os únicos partidos de relevo a lançar candidatos em todas as eleições. Os demais, para todos os efeitos, retiraram-se da disputa direta pela presidência. 
A competição eleitoral é vertebrada pela estratégia dos partidos. Estes agem antes dos eleitores, decidindo em suas convenções quais serão as alternativas à disposição dos eleitores. As decisões tomadas pelos líderes partidários, praticamente, antecipam o segundo turno ao coordenarem suas estratégias. Eleitores votam nas poucas candidaturas que lhes são oferecidas.

Nem semprefoi assim.Aeleição de 1989 foi claramente diversa das demais. Foram 21 candidaturas. Todos os partidos lançaram candidaturas avulsas. Entre os maiores partidos, a exceção foi o PT, o único a ter sua candidatura apoiada formalmente por uma coligação. Ainda assim, o PT juntou-se ao PSB e PCdoB, ambos sem grande expressão eleitoral naquele momento.

A maioria dos partidos buscou seu lugar ao sol com suas próprias forças. O resultado é conhecido. A eleição caracterizou-se por alta fragmentação. A falta de coordenação entre forças afins contribuiu para a imprevisibilidade dos resultados. Lula ameaçou Collor na reta final do $2^{\circ}$ turno, para o qual se qualificara por uma diferença mínima em relação ao terceiro colocado, menos de 500 mil votos, e tendo recebido meros $17,2 \%$ dos votos válidos. Vale notar que tanto Garotinho em 2002 como Marina em 2010 receberam mais votos do que Lula em 1989.

O cenário altera-se radicalmente em 1994. O ponto de partida da mudança precedeo pronunciamento dos eleitores. Aestratégia de partidos-chave muda. Há um número menor de candidaturas e um número maior delas amparadas por coligações. Os dois partidos mais votados estavam à frente de coligações eleitorais, enquanto os principais derrotados, PDT, PMDB e PPR (ex-PDS e atual PP) concorreram sozinhos. Vale lembrar que a relação do PT com o PSB e do PSDB com o PFL (atual DEM) não se esgotou nesta eleição. As coligações provaram-se estáveis e acabaram por se estreitar com o tempo. Tal estratégia de longo prazo,é verdade, foi rompida em $2002 \mathrm{em}$ ambos os lados, mas foi prontamente restaurada em 2006 e reeditada em 2010.0 Quadro I mostra a evolução das candidaturas presidenciais e das coligações que a sustentaram.

No caso do PT, a coligação de 1994 é uma reedição ampliada da coligação formada em 1989. O partido contou desta feita com o apoio do PV, do PPS (ex-PCB) e do PSTU, que se juntaram ao PSB e ao PCdoB. Também foi o único dos partidos grandes a fazer coligações em 1989 e 1994. Tais fatos são suficientes para afastar alguns dos mitos recorrentes acerca do PT, a saber, que sua rigidez ideológica o tornaria infenso a acordos. Sempre foi um partido eleitoral e disposto a ampliaro leque ideológico de seus apoios em troca de votos. Ainda que tenha se movimentado inicialmente no interior da esquerda, o partido não hesitou em se juntar a líderes populistas e comunistas que criticara quando da sua fundação. Assim, quando a origem do partido é levada em conta, tais alianças não deixam de representar uma movimentação em direção ao centro. 
Em 1994, a aliança com o PSB ganhou maior significado eleitoral, uma vez que este crescera com a adesão de Miguel Arraes, candidato ao governo do estado de Pernambuco. O PT, que havia lançado candidato próprio ao governo daquele estado em 1990, deixa de fazê-lo para integrar a coligação capitaneada pelos socialistas.

A ampliação da coligação petista continuou em 1998. Novamente, o partido mostra-se disposto a colher o apoio de líderes populistas, incorporando desta feita o PDT de Leonel Brizola. O preço que o PT se dispôs a pagar pelo apoio do PDT a Lula envolveu uma negociação entre os dois planos da disputa. O PT apoiou a candidatura Garotinho ao governo do Rio de Janeiro pelo PDT, sacrificando a candidatura própria em um estado em que tinha chances de vitória. O PDT retirou-se da campanha presidencial para preservar seu capital eleitoral em estados específicos. Em boa medida, a estratégia do PMDB em 1998 não foi outra: não entrou na disputa nacional para garantir a autonomia de seus candidatos aos governos estaduais.

Nesses termos, a chegada do PT ao poder em 2002 não pode ser creditada a uma alteração radical de sua estratégia de alianças. Para chegar à presidência, o partido sempre se mostrou disposto a fazer alianças com inimigos do passado, como também se mostrou aberto a sacrificar sua penetração e expansão estadual em nome de uma política nacional.A presidência sempre foi sua prioridadee, portanto, nunca hesitou em se mover em direção ao centro e, se pretendia conquistar a presidência, não poderia deixar de fazê-lo. Moveu-se nesta direção ao se juntar ao PSB e ao PDT. O partido abriu suas campanhas presidenciais de 1994 e 1998 acenando para eleitores de centro, moderando seu discurso. Os rumos da campanha foram alterados e as críticas dos puristas ouvidas, quando os resultados das primeiras pesquisas de opinião apontavam para o insucesso da estratégia. Isto é, incapaz de ampliar seu eleitorado, o partido opta por preservar seu eleitorado tradicional. Em 2002, a moderação do discurso deu resultados e a crítica dos puristas pôde ser ignorada.

$\mathrm{O}$ PT esteve confinado à esquerda enquanto a estratégia de seu principal adversário, o PSDB, bloqueou sua movimentação.Achegada do PSDB ao poder em 1994 foi alavancada por sua política de alianças. Como é fartamente sabido, a estratégia do partido para conquistar a presidência foi amparada pela coligação com o PFL, hoje DEM. De um lado, a aliança representou uma guinada do partido em direção à direita. Isto é, o partido construiu uma aliança capaz de romper o isolamento em que se encontrava, estendendo o alcance de seu apelo eleitoral à sua direita. O segundo componente da coligação, talvez até mais importante, envolveu o aspecto regional. Até 1994, salvo a sua cabeça de ponte no Ceará, o partido praticamente não existia no nordeste. Assim, mesmo contando com um importante cabo eleitoral - 


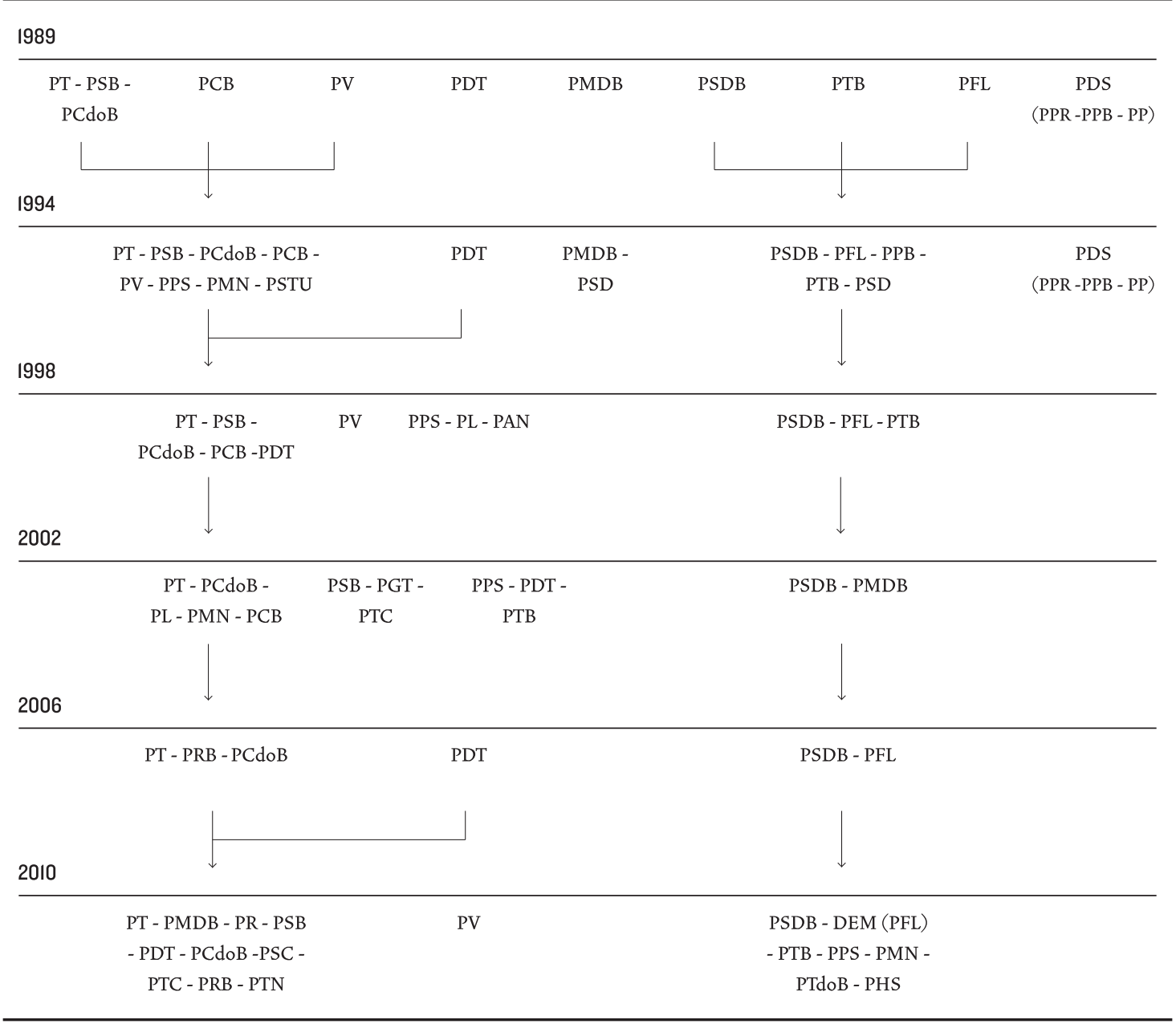

o Plano Real e suas consequências para o poder aquisitivo dos mais pobres - , o PSDB não correu o risco de lançar uma candidatura solo à presidência. As dificuldades de ir além das fronteiras de São Paulo, experimentadas em 1989, estavam vivas nas mentes de seus líderes.

O PSDB, como fez o PT, ampliou seu leque de aliados em 1998, incorporando o PPB (ex-PDS e ex-PPR). A coligação rompeu-se em 2002 com as consequências conhecidas. PSDB e PFL não conseguiram fechar um acordo em torno de candidato comum à presidência. Antonio Carlos Magalhães, que em 1994 havia justificado a aliança com esquerdistas para barrar uma possível vitória petista, declara que o "sapo barbudo" já não era tão perigoso e podia ser digerido, sustentando assim a neutralidade do partido na corrida presidencial após a implosão da candidatura de Roseana Sarney. Da sua parte, José Serra 
sempre soube que não poderia contar com apoio do PFL para chegar à presidência. Já na sucessão da presidência da Câmara em 2000, o pré-candidato construiu uma aliança com o PMDB para compensar a perda do aliado tradicional.

Sem dúvida alguma, as dificuldades no front econômico contribuíram para a derrocada da candidatura tucana. Contudo, a inspeção das votações obtidas pelo candidato estado a estado mostra que a quebra da aliança PSDB-PFL também cobrou seu preço, qual seja, a queda no nordeste foi mais pronunciada do que nas demais regiões. Nas capitais dessa região, a votação do PSB em 2002 é um terço da obtida em 1998.

Em 2006, as velhas alianças foram restauradas. O PSB volta a compor com o PT, embora não tenha integrado formalmente a coalizão que sustentou a candidatura Lula, enquanto o PSDB contou novamente com o apoio do PFL. Os filhos pródigos voltaram ao seio de suas famílias, reconstituindo os dois grandes blocos. O resultado dessas eleições mostrou o efeito da recomposição de forças. As opções fora dos dois blocos são mínimas, resumindo-se a duas dissidências no campo petista (Heloísa Helena e Cristovão Buarque, candidatos do PSOL e do PDT respectivamente, haviam saído do partido) que não chegou a arranhar o controle do PT sobre a esquerda. O PSDB perde as eleições, mas mostra grande poder de recuperação. Em relação a 2002 , o desempenho de Alckmin é excepcional. Obviamente, este crescimento é uma função direta da inexistência de alternativas à direita do PT. O PSDB recupera eleitores que haviam deixado o partido para apoiar Lula, mas também parte dos que haviam migrado para Ciro e Garotinho.

As eleições presidenciais, portanto, são regidas pelas opções oferecidas pelos dois grandes blocos partidários, capitaneados pelo PT e pelo PSDB. Vale observar que as duas alianças se revestem de um claro componente regional. PFL (hoje DEM) e PSB são partidos mais fortes na região nordeste e praticamente ausentes no centro-sul do país. Contudo, no que se refere à penetração no nordeste, a dependência do PSDB para com o DEM é maior do que a do PT em relação ao PSB. O PT nunca mostrou fragilidade no nordeste, antes o contrário. Em 1989 , Lula foi mais bem votado no nordeste do que no sudeste. Sua melhor votação estadual foi em Pernambuco, onde obteve 33,6\% dos votos válidos. Na Bahia, Lula teve 25,9\% dos votos, enquanto em São Paulo o partido ficou apenas um pouco acima da sua votação nacional (17,8\%). Este quadro não se alterou em 1994, quando, para dar um exemplo emblemático, o PT bateu o PSDB em Salvador. Em todas as eleições presidenciais, o desempenho do PT nos centros urbanos do nordeste sempre esteve bem acima da média da votação nacional do partido. Nas pequenas cidades e zonas rurais do nordeste, nos chamados grotões, a votação de Lula nunca se desgarrou da média nacional. Logo, a penetração do PT no nordeste não se deu após a chegada ao poder. Na realidade, 
quando se leva em conta o desempenho de seu adversário direto, o pior desempenho relativo do partido sempre se deu na região sudeste.

A eleição de 2002 registra uma desarticulação na espinha dorsal das duas coligações. Sejam quais tenham sido as forças em operação e, paradoxalmente, a imposição pelo TSE da verticalização das coligações com certeza teve seu peso - os incentivos para a recomposição das principais alianças se fizeram sentir já na eleição seguinte. A análise das votações de Garotinho e Ciro em 2002 revela que ambos esbarraram nas mesmas dificuldades enfrentadas pelas candidaturas solo lançadas no passado: não foram capazes de ir muito além de seus estados natais, Rio de Janeiro e Ceará, respectivamente.

Os altos custos de entrada na disputa presidencial inviabilizam candidaturas que não contam com amparo de coligações partidárias que garantam a presença nos principais colégios eleitorais. Esta é a principal lição da eleição de 1989 , em que muitos candidatos, como Paulo Maluf, Mário Covas e Brizola, tiveram votações expressivas em apenas alguns estados. O PSB e o PPS confrontaram-se com os mesmos limites em 2002. Levando essas dificuldades em consideração, os partidos são induzidos à coordenação pré-eleitoral, costurando coligações partidárias com forte componente regional. Por isso mesmo, as coligações formadas tendem a repercutir sobre as disputas estaduais. As estratégias dos partidos nos dois planos da disputa se entrelaçam. Em 1998, o acordo PT-PDT pode ter sido excepcional e chamou atenção, mas, em 2010 , tal tipo de acordo se tornou a regra. Foi a forma pela qual o PT logrou estender a operação da base de apoio ao governo à eleição. O acordo com o PMDB e o PSB foi abrangente e levou a uma série de retiradas estratégicas de candidaturas, a presidencial de Ciro Gomes pelo PSB aí incluída. Em Minas, o PT não lançou candidato ao governo estadual para garantir sua aliança com o PMDB. O PSDB também construiu seus palanques em quase todos os estados, e onde não tinha força para agir diretamente recorreu ao DEM ou ao PMDB. Em 2010, disputas intrablocos, como a que se deu na Bahia, foram raríssimas.

$\mathrm{Na}$ realidade, ainda que não seja possível desenvolver o ponto neste artigo, tudo indica que a imposição da verticalização das coligações teve efeito contrário ao pretendido, retirando a flexibilidade necessária para a composição e a articulação entre as estratégias nacionais e estaduais dos partidos. O fato é que em 2010 , livre das ingerências legais, a nacionalização das disputas foi bem mais pronunciada do que em 2002 e 2006.

\section{DISPUTAS ESTADUAIS}

O controle do PT e do PSDB sobre as eleições presidenciais não se estende às disputas pelos governos estaduais. Não são os únicos competidores de peso na maioria dos estados e, na realidade, sequer mar- 
cam presença em uma série deles. Em 2006, oito partidos venceram pelo menos uma eleição para o governo estadual. No primeiro turno de 2010 , cinco partidos já conquistaram pelo menos uma governadoria e, dependendo dos resultados do segundo turno, este número pode chegar a nove. Contudo, é preciso ir além das aparências para detectar o processo em curso.

O número de partidos a lançar candidatos ao governo em cada estado permanece relativamente alto. O número médio de candidaturas por estado entre 1990 e 2010 é de 5,5, enquanto a média de partidos participando da eleição para o governo estadual em pelo menos um estado é de 24. Contudo, esses números não levam em conta a viabilidade das candidaturas. Pequenos e micropartidos sem chances de obter votações expressivas distorcem o quadro.

Os principais competidores variam de estado a estado, mas as eleições para governador têm sido basicamente bi-partidárias (Tabela 3). A média de votos recebidos no primeiro turno pelos dois principais partidos nas 27 disputas estaduais está estabilizado em patamares relativamente elevados, acima dos $80 \%$ dos votos válidos. O número de estados em que os dois maiores partidos obtêm menos de $75 \%$ dos votos tem caído sistematicamente desde 2002 , de oito naquela oportunidade caiu para quatro em 2006 e para 2 em 2010 . O número de eleições decididas em segundo turno vem decrescendo a cada eleição, de dezoito em 1994 caiu para apenas nove em $2010^{3}$. São cada vez mais raras eleições que contam com uma terceira força viável e em que os participantes de um eventual segundo turno não sejam conhecidos de antemão. Os terceiros colocados têm, em geral, votações inexpressivas.

$\mathrm{Na}$ realidade, do ponto de vista das votações recebidas, três partidos, PT, PSDB e PMDB, levam nítida vantagem sobre os demais. A votação acumulada desses três partidos nas eleições para os governos estaduais vem crescendo eleição a eleição, passando de 43,5\% em 1990 para 67,2\% em 2006. Há, portanto, uma clara simplificação do quadro partidário nas disputas pelos governos estaduais. Se considerarmos os dois grandes blocos identificados na disputa presidencial, isto é, se tratarmos a votação do PT e do PSB em conjunto, assim como a do PSDB e do DEM, teremos um quadro ainda mais nítido do processo em curso. O bloco PT-PSB mais do que triplicou sua força entre 1990 e 2004 e controla hoje algo como um terço dos votos nacionais nas eleições para governos estaduais. Atualmente, a participação do PSDB-DEM nestas eleições é similar à sua contraparte à esquerda, isto é, recebeu algo como um terço dos votos nacionais. Os demais partidos passaram por um processo de definhamento, obtendo pouco mais de 15\% dos votos válidos nas duas últimas eleições. Temos, portanto, como jogadores efetivos nas disputas pelos governos estaduais, o PMDB e os dois blocos formados pelo PT e PSDB (Tabela 4).
[3] Lara Mesquita nos chamou a atenção para este ponto. 
TABELA 3

Proporção de votos nos dois candidatos mais bem votados.

Eleições para governo estadual - 1990-2010 . em \%

\begin{tabular}{|c|c|c|c|c|c|c|}
\hline \multirow{2}{*}{ UF } & \multicolumn{6}{|c|}{ Ano } \\
\hline & 1990 & 1994 & 1998 & 2002 & 2006 & 2010 \\
\hline$A C$ & 57,0 & 74,1 & 84,0 & 97,2 & 88,2 & 99,7 \\
\hline $\mathrm{AL}$ & 94,4 & 89,4 & 97,0 & 93,1 & 86,4 & 68,7 \\
\hline$A M$ & 92,8 & 92,4 & 98,8 & 73,2 & 90,6 & 89,8 \\
\hline $\mathrm{AP}$ & 71,6 & 76,8 & 75,9 & 62,1 & 91,4 & 57,6 \\
\hline BA & 82,8 & 74,6 & 85,1 & 92,2 & 95,7 & 79,9 \\
\hline $\mathrm{CE}$ & 91,3 & 92,9 & 84,6 & 78,1 & 96,2 & 80,8 \\
\hline DF & 75,8 & 76,8 & 81,9 & 83,8 & 74,3 & 79,9 \\
\hline ES & 79,5 & 74,0 & 75,0 & 95,5 & 99,0 & 97,8 \\
\hline GO & 90,4 & 68,1 & 95,5 & 84,0 & 89,4 & 82,7 \\
\hline MA & 81,1 & 78,0 & 92,4 & 93,6 & 81,1 & 79,6 \\
\hline$M G$ & 57,5 & 75,5 & 81,8 & 88,3 & 99,1 & 96,9 \\
\hline MS & 90,3 & 87,0 & 71,3 & 90,7 & 99,1 & 98,5 \\
\hline MT & 80,7 & 96,5 & 91,9 & 80,2 & 85,2 & 83,1 \\
\hline PA & 82,4 & 75,4 & 39,8 & 63,3 & 81,3 & 85,0 \\
\hline PB & 83,6 & 90,0 & 96,8 & 86,4 & 98,2 & 99,0 \\
\hline PE & 95,7 & 86,7 & 90,5 & 94,5 & 73,0 & 96,9 \\
\hline $\mathrm{PI}$ & 93,7 & 82,3 & 84,3 & 95,0 & 86,9 & 76,5 \\
\hline PR & 70,2 & 93,4 & 98,1 & 57,6 & 81,4 & 98,1 \\
\hline RJ & 78,9 & 67,5 & 81,3 & 75,8 & 65,2 & 86,8 \\
\hline $\mathrm{RN}$ & 87,5 & 91,4 & 91,5 & 67,9 & 98,1 & 88,7 \\
\hline RO & 48,8 & 81,4 & 69,6 & 49,9 & 80,0 & 81,1 \\
\hline $\mathrm{RR}$ & 78,9 & 75,8 & 87,4 & 97,9 & 93,0 & 92,6 \\
\hline RS & 69,3 & 83,9 & 92,3 & 78,4 & 60,3 & 79,1 \\
\hline SC & 80,5 & 79,9 & 82,0 & 69,9 & 81,7 & 77,6 \\
\hline SE & 98,8 & 95,0 & 78,9 & 72,1 & 97,0 & 97,3 \\
\hline SP & 71,7 & 69,1 & 55,2 & 70,7 & 89,4 & 85,9 \\
\hline TO & 86,5 & 95,3 & 94,8 & 94,3 & 98,3 & 100,0 \\
\hline Média & 80,4 & 82,3 & 83,6 & 81,0 & 87,4 & 86,6 \\
\hline Desv & 12,4 & 9,0 & 13,4 & 13,5 & 10,5 & 10,6 \\
\hline Média terceiro & 12,4 & 10,7 & 12,8 & 12,3 & 4,2 & 10,3 \\
\hline
\end{tabular}

Fonte: Banco de Dados Eleitorais do Cebrap/CEM. 
Eleição para governador. Votação Nacional. Partidos selecionados.

\begin{tabular}{|c|c|c|c|c|c|c|c|c|}
\hline \multirow{2}{*}{ Ano } & \multicolumn{8}{|c|}{ Partido } \\
\hline & PT & PSB & PMDB & PSDB & DEM & Outros & PT + PSDB & PSDB + DEM \\
\hline 1990 & $9,7 \%$ & $0,5 \%$ & $22,2 \%$ & $11,6 \%$ & $10,8 \%$ & $45,3 \%$ & $10,2 \%$ & $22,3 \%$ \\
\hline 1994 & $11,7 \%$ & $2,4 \%$ & $17,5 \%$ & $23,2 \%$ & $6,8 \%$ & $38,5 \%$ & $14,1 \%$ & $30,0 \%$ \\
\hline 1998 & $14,5 \%$ & $2,9 \%$ & $22,9 \%$ & $19,9 \%$ & $15,3 \%$ & $24,6 \%$ & $17,4 \%$ & $35,1 \%$ \\
\hline 2002 & $27,6 \%$ & $10,1 \%$ & $12,9 \%$ & $22,9 \%$ & $7,2 \%$ & $19,3 \%$ & $37,7 \%$ & $30,2 \%$ \\
\hline 2006 & $21,9 \%$ & $5,8 \%$ & $18,0 \%$ & $30,1 \%$ & $7,8 \%$ & $16,3 \%$ & $27,8 \%$ & $37,9 \%$ \\
\hline 2010 & $20,1 \%$ & $11,5 \%$ & $18,2 \%$ & $28,9 \%$ & $4,2 \%$ & $16,9 \%$ & $31,7 \%$ & $33,2 \%$ \\
\hline
\end{tabular}

Fonte: Banco de Dados Eleitorais do Cebrap/CEM.

\section{TABELA 5}

Número de governadores eleitos por partido - 1990-2010

\begin{tabular}{c|c|c|c|c|c|c}
\hline \multirow{2}{*}{ Ano } & \multicolumn{7}{c}{ Partido } \\
\cline { 2 - 7 } & PT & PSB & PMDB & PSDB & PFL/DEM & Outros \\
\hline 1990 & 0 & 0 & 7 & 1 & 8 & 11 \\
1994 & 2 & 2 & 9 & 5 & 2 & 7 \\
1998 & 3 & 2 & 6 & 7 & 6 & 3 \\
2002 & 3 & 4 & 5 & 7 & 4 & 4 \\
2006 & 5 & 3 & 7 & 6 & 1 & 5 \\
2010 & 5 & 6 & 5 & 8 & 2 & 1 \\
\hline
\end{tabular}

Fonte: Banco de Dados Eleitorais do Cebrap/CEM.

O PMDB aparece como a terceira força nas disputas estaduais. Sua votação, como se vê na Tabela 4, ainda que com variação significativa em alguns anos, nunca deixou de ser marcante. Ficou abaixo do PSDB e do PT nas três últimas eleições, mas em nenhum momento perdeu contato com os líderes. O PMDB, portanto, é a única força partidária que contrarresta a tendência das disputas estaduais de espelharem a bi-polarização nacional. Contudo, a posição do partido na configuração das disputas estaduais mudou com o tempo.

O controle sobre os executivos estaduais tem ficado restrito aos cinco partidos listados acimadesde pelo menos 1998 (Tabela5). Como se vê, a participação dos demais partidos vem caindo a cada eleição. Nada mais do que 22 estados foram governados por um desses cinco partidos entre 2006 e 2010 . O bloco PT/PSB venceu oito eleições em 
2006, enquanto o PSDB-DEM venceu sete. O PMDB rivaliza com esses blocos, tendo controlado sete estados no último quadriênio.

Os resultados do primeiro turno das eleições de 2010 seguem a mesma toada. O bloco PT-PSB obteve sete vitórias no primeiro turno e passou ao segundo em cinco. O bloco PSDB-DEM obteve seis vitórias em primeiro turno, qualificando-se ao segundo turno em cinco. $\mathrm{O}$ PMDB venceu quatro eleições no primeiro turno e participou de três no segundo turno. O PMN foi o único pequeno partido a vencer no primeiro turno, ao conquistar o governo do Amazonas. Das nove disputas levadas ao segundo turno, PDT, PTB, PP, PPS e PSC participaram em uma cada, apenas. No máximo, portanto, estes partidos poderão controlar um governo estadual nos próximos quatro anos.

Com base nessas informações, é possível reconstituir sinteticamente a estrutura das competições estaduais. Em geral, os partidos de um mesmo bloco não lançam candidatos ao governo em um mesmo estado. O enfrentamento entre membros de um mesmo bloco é a exceção e não a regra. Por exemplo, em 1994, a Bahia foi o único estado em que o PSDB e o PFL lançaram candidatos ao governo, enquanto o PT e o PSB estiveram presentes concomitantemente em dois estados (Rio Grande do Norte e Alagoas). Na eleição seguinte, PT e PSB não se enfrentaram em um estado sequer, o que aconteceu em quatro estados entre o PSDB e o PFL. Nestas duas eleições, o PMDB lançou candidatos em quase todos os estados, em dezenove deles para ser exato, apresentando-se como alternativa aos candidatos dos dois blocos em nove estados em 1994 e em doze, em 1998.

A coordenação do lançamento de candidaturas foi interrompida em 2002 sob o impacto conjunto da ruptura das principais coligações e da imposição de que as mesmas fossem verticalizadas. PT e PSB lançaram candidatos ao governo em quase todos os estados, enfrentando-se em dezoito estados.

Em 2006, o bloco comandado pelo PSDB mostrou-se mais eficiente do que o do PT para evitar disputas estaduais. Três estados assistiram a disputas entre PSDB e PFL, enquanto PT e PSB se enfrentam em seis estados. Contudo, destas nove disputas intrablocos, apenas em três delas um dos partidos envolvidos era mais do que mero figurante na disputa, obtendo mais do que $3 \%$ dos votos. Competição real entre PT e PSB ocorreu apenas em Pernambuco (onde o PFL também apresentou candidato forte) e Rondônia, enquanto PSDB e PFL se enfrentaram para valer no Distrito Federal.

Nesse mesmo ano,o PMDB lançou candidatos em dezesseis estados, sendo que em seis destes os dois blocos também têm pelo menos um representante. Exame dos resultados indica que o PMDB era mero figuranteem um dos estados (São Paulo), enquanto ambos os representantes dos blocos presidenciais não conseguiram marcar presença em dois deles 
(Rio de Janeiro e Goiás).Disputas envolvendo representantes das coligações presidenciais e o PMDB ficaram resumidas ao Rio Grande do Sul, Piauí e Pará.Assim, em geral, a disputa nos estados gira em torno dos representantes diretos dos dois blocos ou se dá entre um destes e o PMDB.

O mapeamento das disputas estaduais em 2010 confere tons mais nítidos ao quadro. Os dois grandes blocos mostraram-se capazes de coordenar suas entradas nas disputas estaduais. PSDB e DEM não lançaram candidatos ao governo estadual em um mesmo estado. PT e PSB tiveram candidatos simultaneamente apenas em São Paulo, onde o candidato do PSB não conseguiu conquistar espaço. Ou seja, os dois blocos foram capazes de evitar o desgaste de lutas internas, retirando candidaturas potencialmente viáveis para unificar palanques. O PT retirou-se da disputa em vários estados em nome de sua aliança nacional com o PSB e o PMDB, fazendo com que o número de candidatos ao governo lançado pela sigla caísse de dezoito para dez.

Em nove estados, o principal confronto deu-se entre representantes diretos dos dois blocos. O PSDB esteve diretamente envolvido em seis destas disputas, enfrentando o PT em três delas (PP, PA e AC) e o PSB nas três restantes (CE, ES e PI). O DEM capitaneou o bloco de direita em três estados, batendo-se com o PT em dois deles (BA e SE) e com o PSB noutro (RN). Há ainda disputas em que um dos blocos está representado por uma força auxiliar, como foi o caso do confronto PSDB-PDT em dois estados (PRe AL) e do PSB-PTB (AP).

$\mathrm{O}$ PMDB, como já vimos, é um capítulo à parte, a única força não engolfada pela clivagem nacional. Contudo, nesta eleição não se apresentou propriamente como força autônoma, se é que o fora em 2006. Em seis estados, alinhou-se com o bloco comandado pelos tucanos, enfrentando o PT em dois deles (MS e RS), o PSB em três (PE, MT, $\mathrm{PB}$ ) e o PV no restante (RJ). Aliou-se à força contrária, isto é, ao bloco comandado pelo PT em três estados e em todos estes seu adversário foi o PSDB (MG, GO, TO).

Poucos estados tiveram suas disputas pelo governo estadual descoladas da lógica que imperou na disputa presidencial (apenas seis, segundo o mapeamento apresentado). Nestes, o PMDB aparece em dois estados, no Maranhão eem Rondônia. Possivelmente, um conhecimento mais detalhado da política estadual permitiria classificação diversa tanto destas como das disputas classificadas acima. Seja como for, parece inegável a inter-relação entre os planos nacional e estadual da disputa eleitoral e a posição pendular do PMDB.

PT e PSDB são os maiores partidos nacionais tanto na disputa pela presidência como nas disputas pelos governos estaduais, sejam estas avaliadas em termos de votos recebidos ou vitórias conquistadas. A relação entre a ascensão nos dois planos da disputa é evidente. O PSDB saltou de 11,6\% em 1990 para 23,2\% em 1994. 
Ganhara a eleição apenas para um governo em 1990; venceu em cinco estados em 1994, incluindo os principais colégios do país, como SP,MG e RJ. O PT, de sua parte, que recebera $14,5 \%$ dos votos para o governo estadual em 1998, pulou para 27,6\% dos votos em 2002 . Os dados para PSB e DEM também mostram a mesma associação: o primeiro cresceu desde a chegada do bloco ao poder nacional, o segundo definhou.

$O$ reverso da medalha merece ênfase. Os demais partidos, como PP, PDT, PTB, PRe tantos outros são meros coadjuvantes nas disputas estaduais. No máximo, são forças auxiliares que se juntam a um dos lados em disputas específicas. A perda de espaço e poder destes partidos são evidentes. Nas últimas eleições, praticamente se retiraram das disputas pelo executivo estadual. Só lançaram candidatos viáveis em alguns poucos estados e, em geral, o fizeram nos de menor expressão.

\section{ELEIÇÕES PROPORCIONAIS}

A redução de partidos viáveis não alcançou as eleições proporcionais. A Câmara dos Deputados mantém sua alta fragmentação, a qual, de fato, continua a crescer. Os cinco partidos que controlam as eleições para cargos executivos não têm o mesmo desempenho naseleições legislativas (Tabela 6). Na realidade, perderam eleitores nas últimas eleições.

Contudo, pelo que foi visto anteriormente, uma parte considerável dos partidos ali representados não alimenta maiores pretensões ou possibilidades de crescimento. Tendo sido excluídos, para todos os efeitos, das disputas pelos cargos executivos, isto é, das eleições em que se decidem os maiores prêmios. Sobrevivem a duras penas, valendo-se de uma política de alianças diversificada estado a estado. Essa fragilidade tem decorrências para as relações entre o Executivo e o Legislativo. É difícil imaginar que partidos nesta situação possam sobreviver fazendo oposição ao governo. Mas esta é outra história.

TABELA 6

Deputado Federal. Votação Nacional dos Principais Partidos. 1994-2010

\begin{tabular}{c|c|c|c|c|c|c|c}
\hline \multirow{2}{*}{ Ano } & \multicolumn{7}{|c}{ Partido } \\
\cline { 2 - 8 } & PT & PSB & PMDB & PSDB & DEM & Subtotal & Outros \\
\hline 1994 & $13,1 \%$ & $2,1 \%$ & $20,3 \%$ & $14,0 \%$ & $12,8 \%$ & $62,3 \%$ & $37,7 \%$ \\
1998 & $13,1 \%$ & $3,4 \%$ & $15,1 \%$ & $17,5 \%$ & $17,3 \%$ & $66,5 \%$ & $33,5 \%$ \\
2002 & $18,4 \%$ & $5,3 \%$ & $13,4 \%$ & $14,3 \%$ & $13,4 \%$ & $64,7 \%$ & $35,3 \%$ \\
2006 & $14,9 \%$ & $6,2 \%$ & $14,4 \%$ & $13,8 \%$ & $10,8 \%$ & $60,1 \%$ & $39,9 \%$ \\
2010 & $16,8 \%$ & $7,1 \%$ & $13,0 \%$ & $11,9 \%$ & $7,6 \%$ & $56,3 \%$ & $43,7 \%$ \\
\hline
\end{tabular}




\section{CONCLUSÃo}

Aestratégia eleitoral dos partidos, ancorada no monopólio queeles detêm sobre o lançamento de candidaturas, formata a competição eleitoral. Cidadãos só podem votar nas opções que lhes são oferecidas. A coordenação das estratégias partidárias tem levado a uma significativa restrição das opções efetivamente disponíveis nas disputas presidenciais e pelos governos estaduais. O multipartidarismo está, para todos os efeitos, restrito às eleições proporcionais.

PT e PSDB são os principais protagonistas das eleições presidenciais.Asseguraram esta posição em 1994 e não a perderam nas eleições subsequentes. Processos eleitorais são dotados de grande força inercial. O alto custo de entrada nas eleições presidenciais desestimula a participação de potenciais desafiantes. Para estes, negociar a troca de apoios pode ser mais vantajoso. Partidos coordenam suas estratégias nos diferentes planos, articulando o lançamento (e a retirada) de candidaturas nos diferentes distritos.

O PMDB ocupa uma posição singular no quadro que se desenha. Para além do PT e do PSDB, éo único partido com implantação em vários estados e capaz de rivalizar em votos com os dois grandes blocos. Contudo, o fracasso das candidaturas presidenciais em 1989 e 1994 alijou o partido desta disputa, reforçando o peso das lideranças estaduais. Muito provavelmente se uma liderança estadual peemedebista tentaralçarvôos mais altos, seu destino será similar ao de Ciro Gomes em 2010. Outras lideranças estaduais estarão dispostas a negociar seu apoio a outras candidaturas presidenciais em nome do apoio destas em seus estados.

A polarização da disputa presidencial foi transplantada aos estados. PT e PSDB também são os mais fortes contendores nas eleições para governador. Recebem mais votos e controlam mais governos do que os demais. Quando não estão presentes, são representados por seus aliados históricos, PSB e DEM respectivamente, ou por uma aliança circunstancial com o PMDB.

Análises do quadro partidário brasileiro tendem a privilegiar as eleições para a Câmara dos Deputados. Os analistas não se cansam de alertar para a fragmentação excessiva que caracterizaria o sistema partidário brasileiro, tido e havido como um dos mais fragmentados do mundo. Nessas análises, contudo, a eleição presidencial e para os governos estaduais são deixadas de lado. Não há boas razões para tanto.

As eleições presidenciais são as mais importantes tanto para os partidos como para os eleitores. Por isso mesmo, devem ocupar o centro das análises. Nesse sentido, o bi-partidarismo que caracteriza as eleições presidenciais merece maior destaque do que a fragmentação na Câmara dos Deputados, sobretudo quando se atenta para seus efeitos na estruturação das demais disputas. 
Recebido para publicação

14 de outubro de 2010

\section{NOVOS ESTUDOS}

CEBRAP

88 , novembro 2010

pp. 21-37
PT e PSDB foram os partidos mais votados nas cinco últimas eleições presidenciais. O domínio desses dois partidos sobre tais eleições não foi ameaçado entre 1994 e 2010 . Terceiras forças ficaram sempre muitos distantes do segundo colocado e não conseguiram repetir seus resultados nas eleições subsequentes. A polarização PT-PSDB na eleição presidencial repercute e reorganiza as disputas pelos governos estaduais. Não por acaso, estas mesmas agremiações são as principais vitoriosas das disputas pelos governos estaduais. O PMDB é o único partido com presença nacional e votos a rivalizar com estes dois partidos. Contudo, nãoéuma força verdadeiramente autônoma, na medida em que representa um dos dois blocos nos estados.

A simplificação do quadro partidário é visível. São poucos os partidos que realmente contam. A clivagem política nacional se reproduz nos estados. PT e PSDB estão presentes, diretamente ou por meio de representantes, em todos os estados. A oferta de candidaturas viáveis pelos partidos se reduz a dois tanto no âmbito nacional como no estadual. O resto é o resto.

FERNANDO LimONGi é professor titular do departamento de Ciência Política da Universidade de São Paulo e pesquisador sênior do Cebrap.

RAFAE L CORTEZ é doutor em Ciência Política pela USP, professor da PUC-SPe consultor da Tendências Consultoria Integrada. 